\title{
Características de carcaça de bovinos Nelore e Caracu selecionados para peso aos 378 dias de idade recebendo alimentação restrita ou à vontade ${ }^{1}$
}

\section{Antonio Gesualdi Júnior², Augusto César de Queiroz ${ }^{3}$, Flávio Dutra de Resende ${ }^{4}$, Guilherme Fernando Alleoni ${ }^{5}$, Alexander George Razook ${ }^{6}$, Leopoldo Andrade de Figueiredo ${ }^{6}$, Ana Cristina Ladeira de Souza Gesualdi ${ }^{7}$, Edenio Detmann ${ }^{3}$}

\author{
1 Parte da tese de Doutorado do primeiro autor, realizada no APTA - SP e UFV - MG. Projeto financiado pela FAPESP. \\ 2 Parque de Alta Tecnologia do Norte Fluminense - TECNORTE, Av. Alberto Lamego 2000, Campos dos Goytacazes - RJ, CEP: $28013-602$ \\ ${ }^{3}$ Departamento de Zootecnia - UFV, Av. PH Rolfs, Viçosa - MG, CEP: 36571-000. \\ ${ }^{4}$ Instituto de Zootecnia, Av. Rui Barbosa s/n, Colina-SP, CEP: 14770-000. \\ 5 Instituto de Zootecnia, Rua Heitor Penteado 56 - Centro, CX P. 60, Nova Odessa. CEP: 13460-000. \\ 6 Instituto de Zootecnia, CAPTA Bovinos de Corte, Sertãozinho-SP. \\ 7 Pós-graduação - LZNA/UENF, Campos dos Goytacazes - RJ, CEP: 28013-602.
}

RESUMO - Avaliaram-se as características de carcaça de bovinos machos não-castrados de três grupos genéticos submetidos a dois planos de alimentação, em confinamento. Utilizaram-se 56 bovinos com idade média de 18 meses. Doze animais foram abatidos no início do experimento e os demais (16 Nelore selecionados, 12 Nelore não-selecionados e 16 Caracu selecionados, com peso vivo médio inicial de 404, 345 e $434 \mathrm{~kg}$, respectivamente), distribuídos em delineamento inteiramente casualizado, em esquema fatorial 2 x 3, composto por dois níveis de alimentação (restrição alimentar: fornecimento de 65 g de $\mathrm{MS} / \mathrm{kgPV}^{0,75}$ por dia e ad libitum: oferta do alimento duas vezes ao dia) e três grupos genéticos. A dieta foi formulada com silagem de milho como volumoso e apresentou relação volumoso:concentrado 50:50. O abate foi realizado quando os animais atingiram $4 \mathrm{~mm}$ de gordura subcutânea, medida por ultra-som. Observou-se efeito da interação nível de alimentação x grupo genético somente sobre a porcentagem de tecido ósseo. O peso e a profundidade da carcaça e os pesos dos cortes dianteiro e traseiro não diferiram entre os grupos selecionados e foram superiores aos dos animais Nelore não-selecionados. O plano $a d$ libitum proporcionou maior rendimento do traseiro. O rendimento de carcaça não sofreu influência da alimentação e, juntamente com a porcentagem do traseiro, foram maiores para os zebuínos. A espessura de gordura subcutânea real e a porcentagem de tecido adiposo foram maiores para os Nelore não-selecionados, enquanto a área de olho-de-lombo e a porcentagem de tecido muscular foram maiores nos bovinos Caracu.

Palavras-chave: confinamento, seleção de Caracu, seleção de Nelore, ultra-som

\section{Carcass traits of genetically improved Nellore and caracu bulls fed ad libitum or feed-restricted}

\begin{abstract}
The objective of this trial was to evaluate carcass traits of 56 bulls from three genetics groups averaging 18 months of age and receiving two feeding levels. Twelve bulls were slaughtered in the beginning of the study and used as reference animals. The remaining 16 genetically improved Nellore, 12 ordinary Nellore, and 16 genetically improved Caracu averaging 404, 345, and $434 \mathrm{~kg}$ of initial body weight, respectively, were randomly assigned to a completely randomized designed with a $2 \times 3$ factorial arrangement (two dietary levels and three genetic groups). Intake was either restricted to 65 g DM/ kg BW0.75 per day or ad libitum. Corn silage was used as the forage component of the diet while ground corn, cottonseed meal, urea, monensin, and a mineral mixture as the concentrate portion of the ration yielding a forage:concentrate ratio of 50:50. The slaughter weight was determined by ultrasound when animals reached an average of 4 mm of subcutaneous fat. Significant feeding regime $\mathrm{x}$ genetic group interaction was observed only for percentage of bone tissue. Carcass weight and depth and weights of fore and hindquarters did not differ comparing the genetically improved breeds but were lower for ordinary Nellore. The highest hindquarter yield was observed for animals fed ad libitum. Dressing percentage was not affected by feeding regime and was higher on Nellore groups; hindquarter percentage also was higher on Zebu animals. Both subcutaneous fat thickness and percentage of adipose tissue were greater for ordinary Nellore while loin eye area and percentage of muscle tissue were higher for Caracu.
\end{abstract}

Key Words: feedlot, genetically improved Caracu, genetically improved Nellore, ultra-sound 


\section{Introdução}

Na elaboração de um plano nutricional para bovinos de corte, é necessário almejar carcaças com alta proporção de músculos, adequada quantidade de gordura e porcentagem mínima de ossos (Berg \& Butterfield, 1976), uma vez que esses fatores, juntamente com os custos da alimentação, são fundamentais à economicidade do sistema.

O estudo da carcaça dos animais tem como finalidade avaliar os parâmetros que podem ser subjetiva ou objetivamente mensurados e que são relacionados a aspectos qualitativos e quantitativos da carcaça (Muller, 1987). A espessura de gordura subcutânea, a área do músculo Longissimus dorsi, as porcentagens das gorduras renal, pélvica e cardíaca, o peso da carcaça e a marmorização são as características mais importantes para a predição da porcentagem de rendimento de carne (Crouse \& Dikeman, 1976). Uma equação de regressão múltipla desenvolvida por estes autores, envolvendo estas cinco variáveis, explica 79,2\% da variação na porcentagem de rendimento de carne.

Alguns trabalhos têm sido conduzidos para avaliação do desempenho e das características de carcaça de animais zebuínos abatidos em vários estádios (Jorge et al., 1998; Nardon, 1998) ou a pesos fixos (Oliveira et al., 1998). Poucos estudos, no entanto, tem sido realizados com zebuínos selecionados ou os autores não têm especificado o grau de melhoramento a que a população foi submetida. Conseqüentemente, pequena atenção tem sido destinada no intuito de se estimar a relação seleção genética x características da carcaça de animais zebuínos.

Segundo Nardon (1998), a seleção praticada no Brasil visa ao maior peso do animal em determinada idade, o que tem refletido em uma série de transformações na bioquímica, fisiologia e endocrinologia do animal, incluindo a ação dos hormônios e determinando a divisão dos nutrientes entre mantença e produção. Desse modo, o potencial para desenvolvimento pode ser alterado e o suprimento de nutrientes deve ser adequado a este processo para manutenção de uma taxa ótima de crescimento. Conseqüentemente, podem surgir alterações na deposição de músculo na carcaça ou de outros tecidos que compõem o corpo do animal e que afetam a produção e a qualidade da carne bovina.

A idade em que se iniciam a deposição de gordura nos bovinos e a velocidade de deposição é determinada pelo manejo alimentar, pela maturidade, pelo sexo e pelo grupo genético do animal, devendo-se considerar que o grupo genético pode significar raça ou cruzamento.

Carcaças com maior proporção de gordura são mais pesadas e apresentam maior rendimento, o que eleva o custo de produção. Segundo Rattray \& Joyce (1976), os ganhos de peso, associados a altas deposições de gordura, apesar de mais eficientes em termos energéticos, são menos eficientes quanto à conversão alimentar associada à pequena deposição de gordura. Isso ocorre porque os tecidos adiposos nos quais ocorre grande parte do aumento do peso vivo, contêm teores mais elevados de matéria seca que os músculos, aproximadamente 80 x 30\% (Lana et al., 1992).

Em termos econômicos, o produtor normalmente é prejudicado no momento da retirada deste excesso de gordura no frigorífico, denominada toillet da carcaça, visto que este material é comercializado posteriormente, sem remuneração ao seu fornecedor.

O rendimento de carcaça tem grande importância econômica, pois é usado nas principais formas de comercialização de bovinos no Brasil. Porém, deve ser utilizado em conjunto com outros parâmetros de fácil medição nos frigoríficos, como o rendimento dos cortes comerciais, pois o valor do rendimento de carcaça é influenciado pelo peso vivo do animal, que, por sua vez, é modificado pelo peso do conteúdo do trato gastrintestinal, que sofre alterações conforme o número de horas em jejum e o tipo de dieta a que os animais são submetidos (Patterson et al., 1995; Owens et al., 1995; Lawrence \& Fowler, 1997), o grupo genético e a maturidade dos animais, a metodologia utilizada na determinação (Jorge et al., 1999) e os pesos das partes não-integrantes da carcaça (Galvão et al., 1991; Peron et al., 1993; Jorge et al., 1997).

A área de olho-de-lombo (AOL), no entanto, não se constitui uma medida de fácil implementação no frigorífico, mas auxilia na estimação do grau de musculosidade e da porção comestível da carcaça, possibilitando melhor avaliação dos efeitos do método de seleção e dos tratamentos idealizados para o experimento.

Dode \& Jardim (1986) utilizaram a AOL para estimar o peso e a porcentagem dos cortes e da porção comestível da carcaça e verificaram que este é um parâmetro de baixo valor. Contudo, Müller (1980) afirma que a AOL, utilizada em conjunto com outros parâmetros, auxilia na avaliação do grau de rendimento em cortes desossados da carcaça.

Objetivou-se neste trabalho avaliar as características de carcaça e a técnica do ultra-som para medida da espessura de gordura subcutânea e da área de olho-de-lombo de bovinos Nelore e Caracu selecionados para peso aos 378 dias de idade, submetidos à alimentação restrita ou à vontade.

\section{Material e Métodos}

O trabalho foi conduzido na Estação Experimental de Zootecnia de Colina, pertencente ao Instituto de Zootecnia, localizada na região norte do estado de São Paulo, a uma 
altitude média de 589 metros, latitude sul de $20^{\circ} 43^{\prime} 5^{\prime \prime}$ e longitude oeste de $48^{\circ} 32^{\prime}$ '38'’.

O clima da região é classificado, segundo Köeppen, como AW, caracterizado como tropical úmido, com estação chuvosa de outubro a março e seca de abril a setembro. A temperatura média do mês mais quente é superior a $22^{\circ} \mathrm{C}$ e a do mês mais frio, superior a $18^{\circ} \mathrm{C}$.

Cinqüenta e seis animais, provenientes da 19a progênie dos rebanhos Nelore (NeS) e Caracu (CaS), foram selecionados ao final da prova de ganho de peso (PGP), com base no peso aos 378 dias de idade (P378) (machos) e no peso aos 550 dias de idade (P550) (fêmeas). Utilizou-se ainda o rebanho de bovinos Nelore no qual não foi aplicado o método de seleção (NeN). Todos os rebanhos foram criados na Estação Experimental de Zootecnia de Sertãozinho do Instituto de Zootecnia de São Paulo.

O período experimental teve início em junho de 2001 e sua duração foi determinada pelo tempo de acabamento dos animais. Assim, quando os animais atingiam no mínimo 4 mm de espessura de gordura subcutânea, avaliada por ultra-som, eram abatidos. O abate do último grupo de animais ocorreu em setembro de 2001.

Os animais foram pesados, identificados com brincos, tratados contra ecto e endoparasitas antes do período de adaptação (28 dias) e, durante esse período, receberam a ração utilizada no período experimental.

Após o período de adaptação, 12 animais (quatro de cada grupo genético) foram abatidos e serviram de referência para os estudos subseqüentes. Os 44 animais restantes, ou seja, 16 NeS, 12 NeN e 16 CaS com peso vivo médio inicial de 404, 345 e $434 \mathrm{~kg}$, respectivamente, entraram no ensaio de alimentação e foram distribuídos individualmente nas baias, conforme a raça. As baias, com área total de $30 \mathrm{~m}^{2}$ e $8 \mathrm{~m}^{2}$ de área coberta, eram providas de comedouro e bebedouro de concreto.

Metade dos animais de cada grupo genético (oito NeS, seis NeN e oito CaS) recebeu alimentação ad libitum até o abate e a outra, alimentação restrita, visando fixar o consumo em 65 g de matéria seca por unidade de tamanho metabólico (65 g de MS/kgPV ${ }^{0,75}$ ), para caracterizar um baixo plano nutricional que possibilitasse ganhos médios diários moderados.

Ao início do experimento, efetuaram-se a pesagem inicial dos animais, após jejum completo de 18 horas, e a avaliação da espessura de gordura subcutânea (EGS), via ultra-som, e o escore corporal. As pesagens, a avaliação por ultra-som e o escore corporal foram feitos no início do período de adaptação e a cada 28 dias.

A avaliação via ultra-som foi realizada entre a $12^{a}$ e e a $13^{\text {a }}$ costelas nos animais contidos em tronco de contenção equipado com tesoura para preensão da cabeça.
O peso final foi determinado no dia do abate, após jejum completo durante 18 horas.

A ração, balanceada com silagem de milho, milho moído, farelo de algodão, uréia, monensina e mistura mineral, apresentou relação volumoso:concentrado 50:50 e foi avaliada para energia e proteína pelo CNCPS, versão 4.0. Os teores de nutrientes digestíveis totais e de energia metabolizável foram de $79 \%$ na matéria seca (MS) e 2,85 Mcal/kg MS, respectivamente. A dieta foi reajustada semanalmente, com base no consumo de MS e na porcentagem de MS do volumoso e do concentrado, e fornecida em duas refeições diárias, às 7 e 16 h. O consumo de alimento foi controlado diariamente, procurando-se manter as sobras em torno de $5 \%$ do oferecido para os animais do tratamento ad libitum.

A proporção dos ingredientes na mistura de concentrados é apresentada por Gesualdi Jr. et al. (2003).

Após o abate, a carcaça foi dividida, utilizando-se uma serra elétrica, em duas meia-carcaças, que foram pesadas individualmente e resfriadas a $-5^{\circ} \mathrm{C}$ por 18 horas. Após esse período, foram novamente pesadas, obtendo-se na meiacarcaça direita os cortes básicos dianteiro, paleta e traseiro. Para determinação da porcentagem dos tecidos da carcaça, utilizou-se a metodologia de Hankins \& Howe (1946). Da meia-carcaça esquerda foram obtidas as medidas de comprimento e profundidade, a área de olho-de-lombo e a espessura de gordura subcutânea real.

O peso corporal vazio (PCVZ) dos animais-referência foi determinado somando-se os pesos de carcaça, sangue, cabeça, pés, couro, cauda, vísceras e órgãos. O valor obtido dos animais-referência, para cada raça, foi utilizado para estimativa do PCVZ inicial dos animais experimentais, estimado, por ocasião do abate, de modo semelhante ao dos animais-referência.

O peso inicial de carcaça dos animais experimentais também foi estimado utilizando-se os valores obtidos dos animais-referência.

O delineamento experimental utilizado foi o inteiramente casualizado, com arranjo fatorial $2 \times 3$, composto por dois regimes de alimentação (restrito e ad libitum) e três grupos genéticos (Nelore selecionado, Nelore não-selecionado e Caracu selecionado). Para comparação das médias, utilizou-se o teste de DMS $(\alpha=0,05)$.

O procedimento de validação da espessura de gordura medida pelo ultra-som foi realizado por meio do ajuste demodelo de regressão linear simples dos valores preditos via ultrasonografia sobre os valores observados. As estimativas dos parâmetros de regressão foram avaliadas sob as hipóteses:
$H_{0}: \beta_{0}=0$
$H_{0}: \beta_{1}=1$
$H_{a}: \beta_{0} \neq 0$
$H_{a}: \beta_{1} \neq 1$ 
No caso de não-rejeição de ambas as hipóteses de nulidade $(a=0,05)$, optou-se pela similaridade entre valores preditos e observados. Em situação contrária, nova equação de regressão foi traçada, suprimindo-se o parâmetro relativo ao intercepto e estimando-se o vício global das estimativas como:

$$
B=(\hat{\beta}-1) \times 100
$$

em que: $B$ = vício global das estimativas (\%); $\hat{\beta}$ = estimativa do coeficiente angular da equação ajustada desconsiderando-se o intercepto; e 1 = valor paramétrico para o coeficiente angular sob a pressuposição de similaridade entre valores preditos e observados.

\section{Resultados e Discussão}

Não se observou efeito de interação grupo genético x regime de alimentação sobre nenhuma das variáveis estudadas ( $\mathrm{P}>0,05)$, à exceção da porcentagem do tecido ósseo $(\mathrm{P}<0,05)$ (Tabela 1$)$.

As médias de mínimos quadrados para peso de carcaça (PCAR), rendimento de carcaça em relação ao peso vivo (RCARPV) ao peso corporal vazio (RCARVZ), comprimento (CCAR) e profundidade de carcaça (PFCAR), pesos de dianteiro (DIANT), ponta-de-agulha (PA) e traseiro (TRAS) e rendimentos de dianteiro (RDIANT), ponta-de-agulha (RPA) e traseiro (RTRAS) são apresentadas na Tabela 2. As médias de mínimos quadrados para as espessuras de gordura subcutânea real (EGSR) e medida pelo ultra-som (EGUS), a área de olho-de-lombo (AOL), as quantidades dos tecidos muscular (MUSC), adiposo (GORC) e ósseo da carcaça (OSSC) e as porcentagens dos tecidos muscular (TM) e adiposo (TA) encontram-se na Tabela 3.

Tabela 1 - Médias de mínimos quadrados para porcentagem do tecido ósseo de bovinos Nelore selecionados (NeS), Nelore nãoselecionados (NeN) e Caracu selecionados (CaS)

Table 1 - Least square means for percentage of bone tissue genetically improved Nellore (GIN), ordinary Nellore (ON) and genetically Caracu (GIC)

Regime de alimentação

Feeding regime

Grupo genético

\begin{tabular}{lccc}
\cline { 2 - 4 } & NeS & NeN & CaS \\
& GIN & ON & GIC \\
\hline $\begin{array}{l}\text { Ad libitum } \\
\text { Ad libitum }\end{array}$ & $14,55 \mathrm{Ba}$ & $14,80 \mathrm{Aa}$ & $14,57 \mathrm{Ba}$ \\
$\begin{array}{l}\text { Restrito } \\
\text { Restrict }\end{array}$ & $15,79 \mathrm{Aab}$ & $14,93 \mathrm{Ab}$ & $16,75 \mathrm{Aa}$ \\
\hline
\end{tabular}

Médias seguidas pela mesma letra minúscula em cada linha e mesma letra maiúscula em cada coluna não diferem entre si pelo teste DMS a 5\% de probabilidade

Means followed by the same small letter in each row and same capital letter in each column do not differ according to LSD test at $5 \%$ of probability.
Os animais NeS apresentaram maiores PCAR e PFCAR, além de maiores pesos do DIANT, PA e TRAS que os NeN, o que pode ser atribuído aos efeitos da seleção nesta raça.

Os pesos destas variáveis foram semelhantes para $\mathrm{NeS}$ e $\mathrm{CaS}(\mathrm{P}>0,05)$, à exceção de $\mathrm{PA}$, em que os $\mathrm{CaS}$ apresentaram maiores valores. O peso dos cortes primários são influenciados pelo PCAR (Berg \& Butterfield, 1976), de modo que animais com carcaças mais pesadas em razão do grupo genético ou do plano nutricional apresentam cortes mais pesados.

Entre as variáveis supracitadas, o nível de alimentação somente não influenciou a PFCAR. Provavelmente, o fator que mais afeta esta característica é o crescimento do esqueleto dos animais e, neste caso, o nível de alimentação tem pequena influência durante a fase de terminação, quando a maior parte do crescimento ósseo está completa.

O RCARPV foi menor para o grupo genético Caracu, porém, semelhante entre os animais zebuínos e os regimes de alimentação. Carcaças com maior quantidade de gordura e, portanto, mais pesadas, permitem que se obtenha rendimento maior, ressaltando-se que a porcentagem de gordura da carcaça geralmente aumenta com o peso de abate. Todavia, isso não significa resultados favoráveis no rendimento dos cortes comerciais, pois o excesso da deposição de gordura na carcaça é o que mais contribui para redução do peso dos animais.

De fato, obsevou-se maior porcentagem de gordura (TA) na carcaça dos animais Nelore (Tabela 3), caracterizando maior precocidade para deposição de gordura nesta raça e contribuindo para a obtenção de maiores RCARPV. No caso da raça Caracu, o menor valor de TA contribuiu para que fossem obtidos menores rendimentos de carcaça.

Recomenda-se que, nas avaliações dos lotes destinados ao abate, seja utilizado o RCARVZ em conjunto com o rendimento dos cortes primários ou básicos, pois o RCARPV é influenciado por inúmeros fatores, destacando-se as condições em que o animal é pesado (jejum ou não, tipo de alimentação, confiabilidade da balança utilizada, entre outros) (Owens et al., 1995), pois influenciam o peso do conteúdo do trato gastrintestinal, alterando o peso vivo, geralmente associado ao peso da carcaça para cálculo de seu rendimento. Este conteúdo é influenciado pelo número de horas em jejum, pelo grau de maturidade do animal e pelo grupo genético. Apesar disso, neste estudo, a variável RCARVZ apresentou o mesmo comportamento do RCARPV e provavelmente a maior deposição de tecido adiposo pelos zebuínos tenha sido a principal causa.

O comprimento da carcaça (CCAR) corresponde à distância entre a curvatura média do osso púbis e o bordo cranial medial da primeira costela (Müller, 1980). O estudo desta variável contribui para a avaliação do quanto uma carcaça é mais compacta que outra. Neste estudo, o CCAR não 
Tabela 2 - Médias de mínimos quadrados para peso de carcaça (PCAR), rendimento de carcaça em relação aos pesos vivo (RCARPV) e de corpo vazio (RCARVZ), comprimento de carcaça (CCAR), profundidade de carcaça (PFCAR), pesos de dianteiro (DIANT), ponta-de-agulha (PA) e traseiro (TRAS), rendimentos de dianteiro (RDIANT), ponta-de-agulha (RPA) e traseiro (RTRAS), em dois níveis de alimentação, para bovinos Nelore selecionados (NeS), Nelore não-selecionados (NeN) e Caracu selecionados (CaS)

Table 2 - $\quad$ Least squares means of carcass weight (CW), carcass yield in relation to body weight (CYBW) and empty body weight (CYEBW), carcass lenght $(C L)$, carcass depth $(C D)$, fore quarter (FQW), ribs (RW) and hind quarter weights (HQW), fore quarter (FQY), ribs (RY) and hind quarter yields $(H Q Y)$, in two feeding regime for genetically Nellore $(G I N)$, ordinary Nellore $(O N)$ and genetically Caracu $(G I C)$

\begin{tabular}{|c|c|c|c|c|c|c|}
\hline \multirow[t]{3}{*}{$\begin{array}{l}\text { Item } \\
\text { Item }\end{array}$} & \multicolumn{2}{|c|}{$\begin{array}{c}\text { Nível de alimentação } \\
\text { Nutritional level }\end{array}$} & \multicolumn{3}{|c|}{$\begin{array}{l}\text { Grupo genético } \\
\text { Genetic group }\end{array}$} & \multirow[t]{3}{*}{ CV (\%) } \\
\hline & Ad libitum & Restrito & $\mathrm{NeS}$ & $\mathrm{NeN}$ & $\mathrm{CaS}$ & \\
\hline & Ad libitum & Restrict & $G I N$ & ON & GIC & \\
\hline PCAR (kg) $(C W, k g)$ & $301,90 a$ & $264,20 b$ & $290,45 a$ & $253,60 b$ & $305,1 \mathrm{a}$ & 9,26 \\
\hline RCARPV (\%) (CYBW, \%) & $58,94 a$ & $58,78 a$ & $58,85 \mathrm{ab}$ & $59,76 a$ & $57,98 b$ & 2,51 \\
\hline RCARVZ (\%) (CYEBW, \%) & $64,93 a$ & $65,50 a$ & $65,50 a$ & $65,87 a$ & $64,27 b$ & 1,91 \\
\hline CCAR $(\mathrm{cm})(C L, \mathrm{~cm})$ & $130,11 \mathrm{a}$ & $123,48 a$ & $128,26 a$ & $122,47 \mathrm{a}$ & $129,65 a$ & 13,07 \\
\hline PFCAR $(\mathrm{cm})(C D, \mathrm{~cm})$ & $41,40 \mathrm{a}$ & $41,17 \mathrm{a}$ & $41,52 \mathrm{a}$ & $40,52 b$ & $41,82 \mathrm{a}$ & 2,93 \\
\hline DIANT (kg) (FQW, kg) & $62,93 a$ & $54,24 b$ & $60,47 a$ & $51,65 b$ & $63,65 a$ & 11,41 \\
\hline PA (kg) $(R W, k g)$ & $18,99 a$ & $15,13 b$ & $17,08 b$ & $14,73 c$ & $19,37 a$ & 12,14 \\
\hline TRAS (kg) (HQW, kg) & $67,19 a$ & $59,24 b$ & $66,06 a$ & $58,10 b$ & $65,49 a$ & 9,15 \\
\hline RDIANT (\%) (FQY, \%) & $41,94 \mathrm{a}$ & $42,10 \mathrm{a}$ & $41,97 a$ & $41,42 \mathrm{a}$ & $42,68 \mathrm{a}$ & 3,70 \\
\hline RPA (\%) (RY, \%) & $12,70 \mathrm{a}$ & $11,71 b$ & $11,85 b$ & $11,83 \mathrm{~b}$ & $12,91 \mathrm{a}$ & 5,89 \\
\hline RTRAS (\%) (HQY, \%) & $46,34 \mathrm{a}$ & $45,16 b$ & $46,11 \mathrm{a}$ & $46,74 a$ & $44,41 b$ & 3,03 \\
\hline
\end{tabular}

Médias seguidas pela mesma letra em cada linha não diferem $(P>0,05)$ entre si pelo teste DMS.

Means followed by the same letter, in a row, do not differ $(P>0.05)$ by LSD test.

Tabela 3 - Médias de mínimos quadrados para as espessuras de gordura subcutânea real (EGSR) e medida pelo ultra-som (EGUS), a área de olho-de-lombo (AOL), as quantidades dos tecidos muscular (MUSC), adiposo (GORC) e ósseo da carcaça (OSSC) e as porcentagens de tecido muscular (TM) e adiposo (TA), em dois níveis de alimentação, para bovinos Nelore selecionados $(\mathrm{NeS})$, Nelore não-selecionados ( $\mathrm{NeN}$ ) e Caracu selecionados (CaS)

Table 3 - $\quad$ Least square means for observed subcutaneous fat thickness (OSFT), and measured by ultrasound (UFT), loin eye area (LEA), muscular tissue weight $(M C)$, adipose tissue weight (AC) and bone tissue weight of carcass (BC), muscular tissue (MT) and adipose tissue percentage (AT), in two feeding regime for genetically Nellore (GIN), ordinary Nellore (ON) and genetically Caracu (GIC)

\begin{tabular}{|c|c|c|c|c|c|c|}
\hline \multirow[t]{3}{*}{$\begin{array}{l}\text { Item } \\
\text { Item }\end{array}$} & \multicolumn{2}{|c|}{$\begin{array}{c}\text { Nível de alimentação } \\
\text { Nutritional level }\end{array}$} & \multicolumn{3}{|c|}{$\begin{array}{l}\text { Grupo genético } \\
\text { Genetic group }\end{array}$} & \multirow[t]{3}{*}{ CV (\%) } \\
\hline & Ad libitum & Restrito & $\mathrm{NeS}$ & $\mathrm{NeN}$ & $\mathrm{CaS}$ & \\
\hline & Ad libitum & Restrict & GIN & ON & GIC & \\
\hline EGR $(\mathrm{mm})(O S F T, \mathrm{~mm})$ & $6,09 a$ & $5,22 \mathrm{a}$ & $5,71 \mathrm{ab}$ & $6,75 a$ & $4,52 b$ & 34,90 \\
\hline EGUS (mm) (UFT, $\mathrm{mm})$ & $4,00 \mathrm{a}$ & $3,30 a$ & $3,86 a$ & $3,60 a$ & $3,49 a$ & 19,80 \\
\hline $\mathrm{AOL}\left(\mathrm{cm}^{2}\right)\left(L E A, \mathrm{~cm}^{2}\right)$ & $73,11 \mathrm{a}$ & $65,46 b$ & $65,25 b$ & $65,66 b$ & $76,94 a$ & 11,42 \\
\hline MUSC (kg) $(M C, k g)$ & $159,74 \mathrm{a}$ & $145,21 b$ & $149,18 b$ & $128,75 c$ & $179,50 \mathrm{a}$ & 10,70 \\
\hline GORC $(\mathrm{kg})(A C, \mathrm{~kg})$ & $92,93 \mathrm{a}$ & $70,60 \mathrm{~b}$ & $91,45 \mathrm{a}$ & $82,42 \mathrm{a}$ & $71,40 \mathrm{~b}$ & 15,90 \\
\hline OSSC (kg) $(B C, k g)$ & $49,23 a$ & $48,41 b$ & $49,82 b$ & $42,43 c$ & $54,20 a$ & 10,36 \\
\hline TM (\%) (MT, \%) & $59,32 a$ & $57,47 b$ & $56,68 b$ & $56,00 \mathrm{~b}$ & $62,51 \mathrm{a}$ & 3,70 \\
\hline TA (\%) (AT, \%) & $27,89 a$ & $24,86 b$ & $28,15 \mathrm{a}$ & $29,13 a$ & $21,83 b$ & 8,61 \\
\hline
\end{tabular}

Médias seguidas pela mesma letra em cada linha não diferem $(P>0,05)$ entre si pelo teste DMS.

Averages followed by the same letter, in a row, do not differ $(P>0.05)$ by LSD test.

sofreu influência do nível de alimentação ou do grupo genético $(\mathrm{P}>0,05)$, corroborando os resultados encontrados por Gesualdi Jr. etal.(2000) e Oliveira etal.(1998), que forneceram níveis crescentes de concentrado na dieta de animais cruzados Limousin x Nelore e Nelore, respectivamente, e não encontraram diferenças entre os tratamentos. Da mesma forma que a PFCAR, maior CCAR está relacionado ao desenvolvimento ósseo, que estaria completo na fase de acabamento, sofrendo pouca influência dos planos nutricionais.

O regime ad libitum proporcionou maior rendimento dos cortes básicos que a alimentação restrita $(\mathrm{P}<0,05)$, à exceção do rendimento de dianteiro $(\mathrm{P}>0,05)$.
O RTRAS foi maior para animais $\mathrm{NeS}$ e $\mathrm{NeN}$ que para os CaS, como também foi observado por Resende et al. (2000) e Faria (2004), nos mesmos tipos de animais, o que pode ser explicado, em parte, pelo fato de que a raça Caracu historicamente sofreu pouca seleção para produção de carne, sendo utilizada como animal de dupla aptidão. Nardon (1998), no entanto, não encontrou diferenças para esta característica nos mesmos grupos genéticos utilizados neste estudo, porém, apresentou os valores para RTRAS como porcentagem da porção comestível, ou seja, retirando aparas e ossos, o que talvez tenha padronizado os valores desta variável, pois, em seu estudo, os CaS apresentaram menores 
porcentagens de aparas e os $\mathrm{NeS}$ e $\mathrm{NeC}$, as menores percentagens de ossos.

Os músculos que amadurecem mais lentamente representam o índice mais confiável para avaliação do desenvolvimento muscular dos animais. O músculo dorsal ou Longissimus dorsi é de maturidade tardia e de fácil mensuração quando se utiliza a área de olho-de-lombo (AOL), o que o torna preferido para avaliação do desenvolvimento do tecido muscular.

Neste estudo, a AOL foi superior para os animais $\mathrm{CaS}$ $(\mathrm{P}<0,05)$ e não diferiu entre os dois tipos de Nelore $(\mathrm{P}>0,05)$, provavelmente pelo fato de os $\mathrm{CaS}$ apresentarem maior desenvolvimento muscular que os Nelore, de acordo com os maiores valores de TM (Tabela 3 ).

Os valores de 65,25 e 65,66 $\mathrm{cm}^{2}$, para $\mathrm{NeS}$ e NeN, respectivamente, foram próximos aos encontrados por Nardon (1998), de 68,2 e 65,9, para bovinos Nelore selecionados e não-selecionados, provenientes da $15^{\underline{a}}$ progênie dos rebanhos de Sertãozinho e abatidos com 480 e 428 kg, respectivamente. Todavia, foram superiores aos obtidos por Jorge et al. (1999), que encontraram o valor de $57,95 \mathrm{~cm}^{2}$, ao abaterem os animais com $450 \mathrm{~kg}$ de peso vivo. Esses autores, no entanto, não especificaram o grau de melhoramento e a base da seleção a que a população foi submetida.

A AOL deve ser utilizada em associação à espessura de gordura subcutânea, para melhorar a confiabilidade das estimativas do grau de musculosidade dos bovinos (Priyanto et al., 1993). Os indivíduos que apresentam as maiores medidas de AOL geralmente possuem menor espessura de gordura subcutânea.

Os valores de espessura de gordura subcutânea medida pelo ultra-som não foram influenciados por nenhum dos fatores, o que era esperado, pois buscou-se abater todos os animais com o mesmo valor estimado por ultra-som. No entanto, a espessura de gordura subcutânea real (EGSR) foi maior nos animais $\mathrm{NeN}$ e menor nos $\mathrm{CaS}$, apresentando diferença significativa $(\mathrm{P}<0,05)$.

Oregime de alimentação não influenciou aEGSR $(\mathrm{P}>0,05)$, possivelmente porque os moderados ganhos de peso dos animais sob alimentação restrita, em torno de $0,675 \mathrm{~kg} / \mathrm{dia}$ (Gesualdi Jr. etal., 2003), foram suficientes para permitir acúmulo de gordura na carcaça. Segundo Luchiari Filho (2000), a deposição de gordura subcutânea inicia-se após as deposições das gorduras renal, pélvica e interna e antes da gordura intramuscular e, portanto, não é tardia. Segundo o autor, quando os animais entram na fase de acabamento, a gordura subcutânea passa a ter grande influência sobre a gordura total.

Crouse \& Dikeman (1976) concluíram que a correlação espessura de gordura subcutânea x porcentagem de carne magra na carcaça varia de $-0,76$ a $-0,79$. Segundo Jardim et al. (1991), para cada aumento na unidade da espessura de gordura subcutânea, houve redução de 1,08\% na porcentagem de músculos da carcaça, comprovando que esta variável é um recurso viável para estimação do peso da gordura da carcaça.

Não houve diferença entre a EGSR de NeS e NeN ( $\mathrm{P}>0,05)$ e os valores de 5,71 e 6,75 $\mathrm{mm}$ foram superiores aos registrados por Oliveira et al. (1998), de 4,05, e Jorge et al. (1999), de 2,77 mm, para bovinos Nelore consumindo dietas com $50 \%$ de concentrado. Os valores estimados neste estudo foram inferiores aos descritos por Nardon (1998), de 8,0 e 8,6 mm, para NeS e NeN, respectivamente. A EGSR pode ser influenciada pela toillet ou pela retirada do couro no frigorífico, o que poderia explicar, em parte, as divergências encontradas na literatura para animais de mesmo grupo genético consumindo dietas semelhantes.

Confirmando os relatos da literatura acerca da AOL e da espessura de gordura subcutânea, os animais Caracu apresentaram os maiores valores de TM e os menores de TA, indicando maior grau de musculosidade desta raça em relação à Nelore, como observado por Faria (2004).

O critério de abate determinado pela medida de ultra-som quando os animais atingiam $4 \mathrm{~mm}$ de gordura subcutânea mostrou-se ineficiente neste estudo, visto que este método subestimou os valores reais da espessura de gordura subcutânea $(\mathrm{P}<0,05)$ (Tabela 4 e Figura 1). Uma possível causa pode ser a falta de alinhamento do transdutor com o ponto de medida, pois, segundo Wilson et al. (1998), o transdutor deve ser alocado precisamente para que as ondas de ultra-som penetrem entre a $12^{\underline{a}}$ e $13^{\underline{a}}$ costelas e não sobre elas.

Silva et al. (2003), em estudo com novilhos Nelore, avaliaram três níveis de concentrado na matéria seca (73, 79 e 85\%) e também encontraram subestimativas da espessura de gordura subcutânea medida pelo ultra-som. Os autores observaram espessura de gordura medida após o abate de $8,5 \mathrm{~mm}$ (média dos tratamentos), portanto, superior à deste estudo. Em contrapartida, Faria (2004), abatendo animais em três pontos de acabamento (3, 5 e $7 \mathrm{~mm}$ ), encontrou valores semelhantes para as espessuras de gordura medidas por ultra-som e após o abate em animais Caracu, Gir e Guzerá selecionados, além dos Nelore não-selecionados. Somente no grupo Nelore selecionado houve subestimativa da espessura de gordura medida pelo ultra-som, porém nenhuma causa foi apresentada para esse resultado.

A falta de acurácia na predição das características de carcaça em alguns trabalhos pode ser decorrente da inexperiência dos peritos na captura e interpretação das imagens. É possível que outros fatores possam estar relacionados, 
Tabela 4 - Estimativas de parâmetros, hipóteses de nulidade e níveis descritivos de probabilidade (Valor P) para a relação entre valores de espessura de gordura subcutânea observados e preditos via ultra-sonografia Table 4 - Estimates of parameters, null hypotheses and descriptive levels of probability (Value $P$ ) for the regression between values of observed subcutaneous fat thickness and predicted by ultra-sound

\begin{tabular}{|c|c|c|c|}
\hline $\begin{array}{l}\text { Parâmetro } \\
\text { Parameter }\end{array}$ & $\begin{array}{c}\text { Estimativa } \\
\text { Estimate }\end{array}$ & $\begin{array}{l}\text { Hipótese de } \\
\text { nulidade } \\
\text { Null } \\
\text { hypothesis }\end{array}$ & $\begin{array}{c}\text { Valor-P } \\
P \text { value }\end{array}$ \\
\hline $\begin{array}{l}\text { Intercepto } \\
\text { Intercept }\end{array}$ & 2,6768 & $\mathrm{~b}_{0}=0$ & $<0,0001$ \\
\hline $\begin{array}{l}\text { Coeficiente inclinação } \\
\text { Slope }\end{array}$ & 0,1750 & $b_{1}=1$ & $<0,0001$ \\
\hline $\begin{array}{l}\text { Coeficiente correlação } \\
\text { linear } \\
\text { Linear correlation } \\
\text { coefficient }\end{array}$ & 0,4654 & $\mathrm{r}=0$ & 0,0015 \\
\hline
\end{tabular}

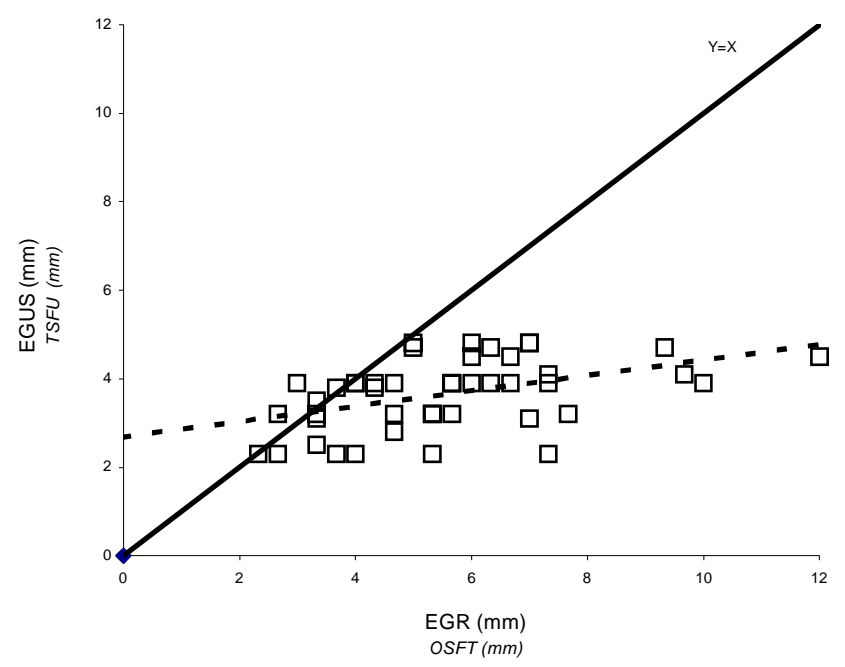

Figura 1 - Relação entre as espessuras de gordura subcutânea observadas (EGSR) e preditas via ultra-sonografia (EGSU). A linha tracejada corresponde à reta de mínimos quadrados.

Figure 1 - Relation between values of observed subcutaneous fat thickness (OSFT) and predicted by ultra-sound (UFT) (the dashed line corresponds to the straight line of the least square).

inclusive as características dos tecidos pós-morte, a remoção de parte da gordura junto com o couro, o deslocamento dos músculos quando os animais foram pendurados, entre outros.

\section{Conclusões}

Os animais dos grupos Nelore e Caracu selecionados apresentaram carcaças mais pesadas.
Os rendimentos de carcaça em relação aos peso vivo e de corpo vazio não foram influenciados pelo regime de alimentação, observando-se que a porcentagem do traseiro foi maior para os zebuínos.

Os animais da raça Caracu apresentaram maior grau de musculosidade que os Nelore, em razão dos maiores valores para área de olho-de-lombo e da porcentagem de tecido muscular.

Nas condições deste estudo, o uso do ultra-som para determinação da espessura de gordura subcutânea subestimou os valores reais para esta variável.

\section{Literatura Citada}

BERG, R.T.; BUTTERFIELD, R.M. New concepts of cattle growth. New York: Sydney University, 1976. 240p.

CROUSE, J.D.; DIKEMAN, M.E. Determinates of retail product of carcass beef. Journal of Animal Science, v.42, n.3, p.584591, 1976.

DODE, M.A.N.; JARDIM, P.O.C. Estimativas dos principais cortes e da porção comestível da carcaça, em novilhos Holandês. Pesquisa Agropecuária Brasileira, v.21, n.7, p.771-776, 1986.

FARIA, M.H. Desempenho, características de carcaça e qualidade da carne de bovinos de diferentes grupos genéticos abatidos em três pontos de acabamento Botucatu: Universidade Estadual Paulista, 2004. 85p. Tese (Doutorado em Zootecnia) - Universidade Estadual Paulista, 2004.

GALVÃO, J.G.; FONTES, C.A.A.; PIRES, C.C. et al. Características e composição física da carcaça de bovinos não-castrados, abatidos em três estágios de maturidade de três grupos raciais. (estudo II). Revista Brasileira de Zootecnia, v.20, n.5, p.502-512, 1991.

GESUALDI JR., A.; PAULINO, M.F.; VALADARES FILHO, S.C. et al. Níveis de concentrado na dieta de novilhos $\mathrm{F} 1$ limousin $\mathrm{x}$ nelore: características de carcaça. Revista Brasileira de Zootecnia, v.29, n.5, p.1467-1473, 2000.

GESUALDI JR., A.; QUEIROZ, A.C.; RESENDE, F.D. et al. Desempenho produtivo de bovinos nelore e caracu selecionados para peso aos 378 dias de idade e nelore comum. In: REUNIÃO ANUAL DA SOCIEDADE BRASILEIRA DE ZOOTECNIA, 40., 2003, Santa Maria. Anais... Santa Maria: Sociedade Brasileira de Zootecnia/Macromedia, [2003]. CD-ROM. Nutrição de Ruminantes.

HANKINS, O.G.; HOWE, P.E. Estimation of the composition of beef carcass and cuts. Washington: USDA, 1946. (Technical Bulletin 926).

JARDIM, P.O.C.; DODE M.N.A.; OSÓRIO. J.C.S. et al. Estimativa da composição física de novilhos Holandês PB. Pesquisa Agropecuária Brasileira, v.26, n.8, p.1193-1199, 1991.

JORGE, A.M.; FONTES, C.A.A.; SOARES, J.E. et al. Características quantitativas da carcaça de bovinos e bubalinos abatidos em diferentes estádios de maturidade. Revista Brasileira de Zootecnia, v.26, n.5, p.1039-1047, 1997.

JORGE, A.M.; FONTES, C.A.A.; PAULINO, M.F. et al. Desempenho produtivo de animais de quatro raças zebuínas, abatidos em três estádios de maturidade. 1. Ganho de peso e de carcaça e eficiência de ganho. Revista Brasileira de Zootecnia, v.27, n.4, p.766-769, 1998.

JORGE, A.M.; FONTES, C.A.A.; PAULINO, M.F. et al. Desempenho produtivo de animais de quatro raças zebuínas, abatidos em três estádios de maturidade. 2. Características da carcaça. Revista Brasileira de Zootecnia, v.28, n.1, p.381-389, 1999.

LAWRENCE, T.L.J.; FOWLER, V.R. Growth of farm animals. London: Cambridge University, 1997. 330p. 
LANA, R.P.; FONTES, C.A.A.; PERON, A.J. et al. Composição corporal e do ganho de peso e exigências de energia, proteína e macroelementos minerais ( $\mathrm{Ca}, \mathrm{P}, \mathrm{Mg}$, Na e K) de novilhos de cinco grupos raciais. I. Conteúdo corporal e do ganho de peso em gordura, proteína e energia. Revista da Sociedade Brasileira de Zootecnia, v.21, n.3, p.528-537, 1992.

LUCHIARI FILHO, A. Pecuária da carne bovina. São Paulo, 2000. 134p.

MÜLLER, L. Normas para avaliação de carcaças e concurso de carcaças de novilhos. Santa Maria: Universidade Federal de Santa Maria, 1980. 31p.

NARDON, R.F. Seleção de bovinos para desempenho: composição corporal e características de carcaça. Jaboticabal: Universidade Estadual Paulista, 1998. 99p. Tese (Doutorado em Zootecnia) - Universidade Estadual Paulista, 1998.

OLIVEIRA, S.R.; COELHO DA SILVA, J.F.; VALADARES FILHO. S.C. et al. Rendimentos de carcaça e cortes básicos de novilhos Nelore recebendo rações com diferentes níveis de concentrado. In: REUNIÃO ANUAL DA SOCIEDADE BRASILEIRA DE ZOOTECNIA, 35., 1998, Botucatu. Anais... Botucatu: Sociedade Brasileira de Zootecnia, 1998. p.164.

OWENS, F.N.; GILL, D.R.; SECRIST, D.S. et al. Review of some aspects of growth and development of feedlot catle. Journal of Animal Science, v.73, n.10, p.3152-3172, 1995

PATTERSON, D.C.; STEEN, R.W.; KILPATRICK, D.J. Growth and development in beef cattle. 1. Direct and residual effect of plane of nutrition during early life on components of gain and food efficiency. Journal of Agriculture Science, v.124, n.1, p.91-100, 1995.

PERON, A.J.; FONTES, C.A.A; LANA, R.P. et al. Rendimento de carcaça e de seus cortes básicos e área corporal de bovinos de cinco grupos genéticos, submetidos à alimentação restrita e "ad libitum". Revista Brasileira de Zootecnia, v.22, n.2, p.238-247, 1993.
PRIYANTO, R.; JOHNSON, E.R.; TAYLOR, D.G. Prediction of carcass composition in heavy-weight grass-fed beef catle. Animal Production. v.57, n.1, p.65-72, 1993.

RATTRAY, P.V.; JOYCE, J.P. The utilization of metabolizable energy of fat and protein deposition in sheep. New Zealand Journal of Agricultural Research, v.19, p.299, 1976.

RESENDE, F.D.; NARDON, R.F.; RAZOOK, A.G. et al. Desempenho e características de carcaça de zebuínos e caracu selecionados para peso aos 378 dias de idade, submetidos a dois níveis de energia na terminação. In: REUNIÃO ANUAL DA SOCIEDADE BRASILEIRA DE ZOOTECNIA, 37., 2000, Viçosa, MG. Anais... Viçosa, MG: Sociedade Brasileira de Zootecnia/Gnosis, [2000]. CD-ROM. Nutrição de Ruminantes. 0507

SILVA, S.L.; LEME, P.R.; PEREIRA, A.S.C. et al. Correlações entre características de carcaça avaliadas por ultra-som e pós-abate em novilhos nelore, alimentados com altas proporções de concentrado. Revista Brasileira de Zootecnia, v.32, n.5, p.1236-1242, 2003.

WILSON, D.E.; GRASSER, H.U.; ROUSE, G.H. et al. Prediction of carcass traits using live animal ultrasound. In: WOLRD CONGRESS ON GENETICS APPLIED TO LIVESTOCK PRODUCTION, 6., 1998, Armidale. Proceedings... Armidale: 1998. p.61-68. 